\title{
Cepillando la historia a contrapelo: un análisis decolonial de la lucha indígena misak ${ }^{1}$
}

\section{Specifying the history against the grain: a decolonial analysis of the indigenous struggle misak}

pp. $9-26$

Carlos Alberto Dávila²

REC: 03/06/2021 ACEP: 06/07/2021

\section{Resumen}

La lucha indígena en el departamento del Cauca (Colombia) ha significado el mayor proceso de resistencia étnica que se ha generado en la historia del país. Es por ello que este artículo muestra una realidad geosociohistórica que sigue transformando el orden estatal, confrontando y tensionando el viejo orden moderno que desde el siglo XIX se constituyó en cimiento de la realidad de la nación colombiana. A raíz de lo anterior, esta experiencia investigativa tiene un enfoque etnográfico hermenéutico, permitiéndose con ello acercarse a la comunidad indígena misak, ubicada en dicho departamento y la cual ha hecho parte de la resistencia indígena con el fin de recuperar la tierra, el territorio, así como derrotar el colonialismo y la colonialidad, fenómenos que determinaron de manera histórica la inferioridad, la opresión y la subalternización de esta comunidad.
Palabras clave: memoria, colonialismo, colonialidad, raza, nación, pasado.

\section{Abstract \\ The indigenous struggle in the department of Cauca (Colombia) has meant the largest process of ethnic resistance that has been generated in the history of the country. For this reason, this article shows a geosocio- historical reality that continues to transform the state order, confronting and stressing the old modern order that since the 19th centu- ry became the conflict of the reality of the Colombian nation. As a result of the above, this investigative experience has a herme- neutical ethnographic approach, allowing it to approach the Misak indigenous commu- nity, located in said department and which has become part of the indigenous resistance in order to recover the land, the territory, as}

1. Artículo derivado de investigación.

2. Doctor en Estudios Territoriales y magíster en Derecho. Profesor investigador en el Centro de Investigaciones en Desarrollo Sostenible y Medio Ambiente de la Universidad de Manizales. Correo electrónico: cadavilac@umanizales.edu.co. Orcid: http:// orcid.org/ 0000-0002-7291-1976 
well as defeating colonialism and coloniality phenomena, that historically determined the inferio rity, oppression and subalternization of this community.

Keywords: memory, colonialism, coloniality, race, nation, past.

\section{Introducción}

Cuando estudiamos los significados de la memoria colectiva e histórica, emergen alrededor de los mismos una serie de acontecimientos que guardan relación con los genocidios cometidos en las Américas, en África y en Europa en contra de pueblos y comunidades que, por su condición cultural, política, económica e ideológica fueron despojados de su condición de humanidad.

Ante estos actos, autores como Lévinas (2012), Mèlich (2001), Walsh (2012, 2020), Mbembe (2016, 2020), Arendt (2019), Santos (2020), Grosfoguel (2020) y Dávila (2020, 2021) advierten la necesidad de crear un pensamiento crítico en donde se aborde una ética de la memoria, la cual se concibe como una ética abierta al tiempo (pasado, presente, futuro) que posibilite la comprensión de lo imprevisible y el agotamiento del otro en el afán de construir una "pedagogía que coloque a la narración y a la memoria en el centro de la acción" (Mèlich, 2001, pp. 11-12).

Para estos autores, este pensamiento crítico debe nacer del relato que irrumpe desde la experiencia de aquellos que hasta nuestros días se consideran como supervivientes de la violencia, experiencia que, según Mèlich (2001), "surge del recuerdo del pasado que es, al mismo tiempo, la posibilidad del futuro y, por tanto, de la utopía" (p. 12). Bajo este supuesto, Lévinas presenta la necesidad de construir una fenomenología de la memoria que se sitúa en los márgenes; es decir, la memoria se proyecta como locus de enunciación que permite encontrarnos con un sujeto que no parta del "cuidado de sí sino como cuidado del otro" (Lévinas, 2012, p. 222). En otras palabras, un otro que se presenta en la historia como trascendencia y exterioridad.

Ante la presencia de un otro en la historia, el filósofo judío-alemán Walter Benjamin (2009), propone en su tesis VII "cepillar la historia a contrapelo". Con esta tesis, Benjamin pone como condición el no aceptar al cortejo triunfal propio de la versión oficial y dominante de la historia, de allí que este pensador de la escuela de Frankfurt advierta que debemos recurrir a la memoria de las víctimas permanentes de los sistemas de dominación: los esclavos, los campesinos, las comunidades indígenas y afrodescendientes, las mujeres y a las minorías religiosas, pues son estos quienes han resistido y han luchado en contra de la dominación, y que aun siendo derrotados una y otra vez serán sus memorias las que hacen posible construir las luchas de liberación del presente.

Es por eso que, al intentar abordar la memoria desde el contexto latinoamericano, resulta ineludible preguntarnos sobre la misma como un constructo político de los pueblos oprimidos que emerge desde las grietas de un modelo occidental-moderno, sostenido por las ideas de continuidad, causalidad y progreso en el marco del colonialismo, la colonialidad, el capitalismo y el patriarcalismo (Santos, 2020; Quijano, 2014), construyendo un ciclo hegemónico que se puede definir como un proceso de "dirección política y cultural de un grupo social sobre otros segmentos sociales, subordinados a él" (Gramsci, 2013, p. 11).

Desde esta perspectiva, en este artículo de investigación se mostrarán "las luchas memoriales misak", entendiendo que la 
memoria para este pueblo originario emerge no solo como prácticas para dar sentido a la existencia colectiva de un pueblo, sino que advierte la presencia y permanencia de lo que fue denominado por el líder indígena ecuatoriano Luis Macas como "la matriz de poder colonial", la cual se ha instaurado como proyecto histórico en América Latina y de manera particular en Colombia mediante una serie de prácticas políticas, económicas, culturales y territoriales que provocaron profundos desgarramientos en lo comunitario así como en la subjetividad de pueblos como el misak.

De este modo se expondrá a la memoria misak como un espacio-tiempo que es constitutivo de la resistencia y de la re-existencia, dado que la memoria de este pueblo irrumpe como proceso geosociohistórico, presentándose en el escenario del Estado-nación como una memoria caminante, en contraposición a la memoria de la cultura hegemónica moderna que intenta poner a la misma como obra de museo.

Por lo tanto, la memoria misak se manifiesta como constructo de la organización política, social y territorial para así instaurarse como práctica y estrategia pedagógica permanente que tensiona las políticas coloniales que se reproducen a través de un sistema de clasificación social basado en la categoría raza, denominado por Quijano (2014) como "colonialidad del poder".

Es por ello que este escrito tiene como propósito mostrar la existencia de una lucha que se instauró en el departamento del Cauca ante las lógicas violentas de marginalización, exclusión y racialización propias de las racionalidades moderno-coloniales, que permanecen mediante la imposición de una conciencia y unos valores que marcaron significados dominantes, los cuales siguen creando discursos que sustentan la incivilidad, inferioridad y el subdesarrollado de los pueblos oprimidos 0 , en el mejor de los casos, como comunidades que deben ser integradas al proyecto de Estado-nación.

\section{Metodología}

Durante su formación y trayectoria académica el autor tuvo la oportunidad de escuchar a Lorenzo Muelas, a Liliana Pechené y a Jeremías Tunubalá, miembros de la comunidad misak, quienes expresaban una crítica frente a los derechos reconocidos por la Constitución Política de 1991 en relación con el tema de su tesis doctoral que era la jurisdicción especial indígena. Adicionalmente, y para comprender la cultura misak, fue necesario acercarse a los trabajos etnográficos realizados por los antropólogos Luis Guillermo Vasco y Víctor Bonilla en la década de los setenta, los cuales le permitieron aproximarse al desarrollo de la lucha histórica de esta comunidad, que tenía como fin la recuperación de la tierra, siendo entendida esta por los mismos misak como un proceso geosociohistórico que, desde la mitad del siglo XX, se consolidó a través de la resistencia indígena emprendida por el líder Manuel Quintín Lame.

Los aportes etnográficos de estos antropólogos evidenciaron la importancia de comprender la trayectoria de resistencia y de lucha del pueblo misak que en la actualidad y ante todo reclama un diálogo intercultural que permita el reconocimiento de sus prácticas territoriales, a fin de identificar no solo a los actores sino también la configuración de relaciones de poder que fueron confrontadas en el primer y más importante alzamiento indígena en la historia colombiana ${ }^{3}$, el cual condujo a la recuperación de la tierra y a la participación en la Asamblea Nacional Constituyente que dio origen a la reforma de 1991 y al reconocimiento de los derechos de los 
pueblos indígenas, reconocimiento que fue común a muchos países de América Latina.

Si bien la investigación base de este artículo fue consolidada a partir de una "etnografía decolonial" (Olivera, 2014; Rappaport, 2007), donde no solo bastó con seleccionar y referenciar posturas teóricas derivadas de la perspectiva modernidad/ colonialidad (Quijano, 2000; Mignolo, 2007; Grosfoguel, 2012; Walsh, 2012) sino también las provenientes de los estudios territoriales críticos (Foucault, 2006; Haesbaert, 2011; Mançano, 2011), en este documento se intenta evidenciar la necesidad de interpretar, desde la teoría crítica decolonial, al colonialismo y la colonialidad del poder como un proyecto geosociohistórico que persiste en la época republicana.

Es por ello que en este artículo se asume la lucha histórica misak como un tiempo de imaginación política epistemológica que "pretende refundar la imaginación política y reforzar las luchas sociales contra la dominación" (Santos, 2020, p. 9); de allí el imperativo de cepillar la historia indígena del Cauca a contrapelo. Para poder lograrlo, la etnografía brindó herramientas para comprender e interpretar cómo un proceso de lucha histórica por la tierra se vincula con la emergencia del pasado y la memoria misak, inaugurando la coexistencia conflictiva con la gubernamentalidad ${ }^{4}$ del Estado-nación colombiano. Para alcanzar lo anterior, este trabajo etnográfico encontró soporte en lo que Giddens (1987) llamó una "metodología hermenéuticamente informada" (p. 11), permitiendo comprender que no se podía abordar a la comunidad misak y sus hechos sociales como lo hacemos con los objetos y eventos del mundo natural, puesto que esta comunidad existe, es creada y recreada por medio de sus propias acciones; es decir, la hermenéutica conlleva a recuperar al sujeto-misak como un ser actuante y razonante.

Esta aproximación posibilitó no solo interpretar el significado de estas prácticas como acciones fundamentadas en un acervo espiritual-ancestral, que siendo una práctica comunitaria situada construye y reconstruye la memoria misak, sino como "arreglos históricos, es decir, [como] productos convencionales" (Jimeno, 2012, p. 13) recreados en el territorio, en el espacio y en el lugar por personas específicas, "a menudo confrontados en jerarquías y luchas de poder" (Jimeno, 2012, p. 13).

En suma, la etnografía y la hermenéutica posibilitaron acercarse con "familiaridad" a las prácticas sociales y culturales de la comunidad misak a través de un proceso mediado por la observación, el registro y la interpretación que no se agota en la descripción de un objeto estático dado que "el trabajo etnográfico que se desprende de ella busca entender a las culturas en su contemporaneidad, pues sabe que las culturas son construcciones dialécticas social e históricamente situadas" (Guerrero, 2002, p. 15).

De esta manera, la apertura hacia el Otro que es distinto, se revela como una dimensión de realidad que no está incluida en mi mundo pero que interpela como otredad.

3. Este alzamiento indígena corresponde a la década de los años setenta, cuando los pueblos originarios del Cauca reclaman su derecho a la tierra, al territorio y a sus orígenes bajo el lema "recuperar la tierra para recuperarlo todo".

4. La gubernamentalidad desde la mirada de Michel Foucault (2006) debe ser entendida como el conjunto constituido por las instituciones, los procedimientos, análisis y reflexiones, los cálculos y las tácticas que tienen como blanco a la población. De igual manera, la gubernamentalidad, nos dice Foucault, guarda relación con el gobierno, la soberanía y la disciplina, produciendo una serie de aparatos-saberes para el ejercicio de las relaciones de poder. 
Desde esta perspectiva, la memoria misak se presenta en este artículo de investigación como materialización de la alteridad y como expresión de otro modo de vida que identifica la lucha memorial como parte esencial de la vida comunitaria.

A partir de lo anterior, fue necesario reconstruir parte de la trayectoria histórica de la comunidad misak, su relación con el contexto, pero también los significados, las representaciones y especialmente el vínculo con la memoria a través del trabajo de campo, observación participante y no participante.

\section{Geografía andina, raza y nación: El proyecto histórico criollo}

Si bien desde la década de los noventa el Estado colombiano ha intentado mostrarse como partícipe de las rupturas históricas-coIoniales a través de las innovaciones constitucionales que garantizan el reconocimiento de derechos para los pueblos originarios, las relaciones de poder que se configuraron desde el siglo XIX mediante el proyecto criollo de sujeción del indígena fue consolidando de manera estructural para el desarrollo de la nación un efecto adverso denominado "la matriz de poder colonial". Esta matriz se configura a partir de una serie de dispositivos que hacen perdurar lo que Katherine Walsh (2012) señala como "la tara colonial de la razón moderno-occidental" (p. 95).

Si bien Colombia vivió en el siglo XIX su proceso emancipatorio dada su condición colonial, los discursos que se mantienen en el devenir del Estado y la nación se enmarcan en un paradigma político, social, económico y territorial moderno en donde el mundo indígena sigue siendo considerado como sinónimo de incivilidad, quedando de manifiesto que para los criollos (hombres blancos, ciudadanos y civilizados) los pueblos originarios constituían un espacio de inferioridad en su proyecto moderno de Estado-nación.

De este modo, el indígena emerge para la sociedad emancipada del siglo XIX como el salvaje, el cual tiene como condición su carencia de humanidad, lo que conduce a que el sujeto-indígena sea incapaz de constituirse en alteridad; es decir, lejos de considerase como una "amenaza civilizatoria, es tan solo una amenaza de lo irracional" (Santos, 2003, p. 74).

Por lo tanto, el valor de estos pueblos se pone de manifiesto cuando desde su presencia tensionan la aspiración de unidad política de la nación o cuando los territorios ocupados por estas comunidades son una vía de acceso a los recursos de la naturaleza, lo cual representa una profunda relación con los fines del colonizador, desprendiéndose de allí la esclavitud, el genocidio, la apropiación por despojo de la tierra, el territorio y el cuerpo, así como la intención de "asimilarlos o convertirlos en ciudadanos intitulados de derechos individuales" (Yrigoyen, 2011, p. 140), mediante la disolución de sus comunidades.

Con el fin de justificar la exclusión y la asimilación (inclusión) de estas comunidades, las élites criollas usaron diferentes tendencias ideológicas, las cuales fueron sustentadas "apelando a la ciencia, o a ciertas ideas políticas modernas de nación (republicanismo, nacionalismo y liberalismo)" (Cuchumbé, 2012, p. 23), y a patrones culturales en donde se pondría de manifiesto la superioridad de la raza blanca como dispositivo fundamental para alcanzar la ciudadanía.

Como resultado de este proceso de racionalidad que se constituyó desde el siglo XVII en el monólogo de la razón moderno-occidental, el pensamiento político, social, territorial y económico de la naciente nación 
fundó un proyecto hegemónico que se puede comprender como un programa de dirección política y cultural creado por la élite criolla, mediante la imposición de una memoria colectiva y de un relato histórico en donde el pasado indígena se presentaría como muerto.

De esta manera, la idea de conciencia de sí indígena estaría ante el "signo de lo ya acabado"; es decir, el lugar de la memoria y de la historia de estas comunidades entraría en el mundo de la "totalidad" que puede entenderse como un proceso de generalización de lo propio y subordinación de lo ajeno en donde la conciencia y los valores son impuestos desde la raza, la clase, el género y el territorio, dispositivos que son utilizados para la construcción de "significados dominantes que conviven con significados subalternos y dominados" (Gramsci, 2013, p. 11).

La nación civilizada e "imaginada" (Anderson, 2011) emerge como un pacto de élite, que tendrá como fin la consolidación de un modo de vida y de un orden sociopolítico que excluye cualquier asomo de diversidad, legitimando la expulsión de lo distinto. Como lo expresa Delfín Grueso (2009), el modo privilegiado de esta exclusión fue el "levantamiento de fronteras simbólicas que invisibilizaban toda expresión cultural que no cupiera dentro de cierto entendimiento de lo que es una nación civilizada" (p. 1).

Estas fronteras simbólicas pueden ser concebidas como una especie de determinismo geográfico y climático que tiene como fin el "progreso de la nación", el cual se sustenta en la superioridad racial del hombre-blanco-propietario. Este escenario de progreso estará unido al profundo interés por el estudio de la naturaleza, el cual fue convertido por la élite criolla en un discurso que guardaría relación con un "protonacionalismo romántico" (Múnera, 2020, p. 88) que tuvo lugar en la consolidación del Estado y la nación a raíz de las discusiones científicas dadas en Europa, las cuales tenían como centro demostrar la "naturaleza inferior de los habitantes de América" (...).

Como lo describe Múnera (2020), la reacción de la élite criolla ante el discurso de inferiorización creó nuevas formas de aprensión del espacio que contribuyeron al desarrollo de identidades nacionales, las cuales guardaron una profunda subordinación con los espacios coloniales supuestamente transformados tras la campaña libertadora, lo que significó revivir el colonialismo que se suponía había partido con el imperio español, para imponerlo como una "estructura, un ethos y una cultura que se reproduce día a día en sus opresiones y silenciamientos, a pesar de los intentos de transformación radical que pregonan las élites político intelectuales sea en versión liberal o populista" (Rivera, 2018, p. 25).

En la imposición de este ethos político, la geografía jugó un papel fundamental a través del discurso promovido por Francisco José de Caldas, quien quizás fue el creador en nuestro medio del discurso de la "superioridad de la república andina" (Múnera, 2020, p. 93). Este discurso representará en el transcurrir de la historia colombiana la configuración de un orden territorial que podemos denominar como una "geografía física racializada" en cuanto la ubicación geográfica de los pueblos originarios servía como justificación de la inferiorización de los mismos. Caldas diría que: "los valles y las mesetas de las grandes cordilleras encarnaron el territorio ideal de la nación, y las costas, las tierras ardientes de los valles ribereños, los llanos y las selvas el «otro», la imagen negativa de una América inferior" (Múnera, 2020, p. 93).

A través de la consolidación de una geografía física, moral y racista se empieza a 
sustentar un orden territorial racializado que se divide en "zonas del ser y del no ser" (Fanon, 2011). Esta zonificación territorial es sustentada por las élites criollas en cabeza de Francisco José de Caldas, a través del racismo científic $0^{5}$ y el determinismo geográfico, teniendo como fin instaurar un régimen soberano a partir de la pureza de la raza, aspiración que emerge desde las cordilleras de los Andes, territorio que, según Caldas, estaba dotado de manera natural para "dar nacimiento a un hombre física, intelectual y moralmente igual al europeo" (Múnera, 2020, p. 95).

Esta geografía racializada introduce una "gramática moral", teniendo como función unos "marcos rituales que establecen órdenes de ser, de pensamiento, de lenguaje y de acción" (Mèlich, 2015, p. 51), que, a su vez, dotan de poder los horizontes de significado del Estado y la nación para la construcción de una identidad única y verdadera. En palabras de Mèlich (2015), estos marcos nos dicen "qué somos y una vez que nos ha creado nos dictan cuáles son nuestros derechos y deberes" (p. 51).

Es por ello que la zona andina sería recreada por la élite criolla como ejemplo de una sociedad civilizada, como zona del ser, habitada por el hombre-blanco-propietario. De este modo, el nuevo proyecto de civilización-modernidad partió de la "piel blanca de los pueblos andinos", trayendo consigo otros elementos culturales como el pudor de sus gentes, las normas de recato, las formas de vestir, las cuales serían expuestas como características fundamentales para adquirir el estatus de hombre-moderno-civilizado ciudadano, quien a su vez será presentado como el fiel representante de una "sociedad bien formada", caracterizada por el "férreo dominio de la ley y de la religión" (Múnera, 2020, p. 97).

De esta manera, el poder soberano y el poder pastoral se entrecruzan en este contexto como una naciente teoría de la soberanía ${ }^{6}$, la cual sirve de sustento a la incipiente gubernamentalidad, que tiene como fin mostrar al ciudadano como individuo dotado de derechos, capacidades que según Foucault (2008) deben convertirlo en sujeto-súbdito-población; es decir, "como elemento sometido a una relación de poder" (p. 49).

Frente a lo anterior, la gubernamentalidad criolla establecida y sustentada desde la geografía racializada instaura un momento de unidad fundamental alrededor del nuevo sujeto-objeto que es la población. Parafraseando a Foucault (2006), lo que se pone de manifiesto es la pregunta moderna sobre el cómo gobernar, que es "precisamente el arte de ejercer el poder" (p. 121). Por lo tanto, nace para la élite la necesidad de fundar una "unidad esencial del poder, el

5. Para autores como Grosfoguel (2012) y Wieviorka (2009), esta primera etapa del racismo científico mediante la cual se intenta mostrar representaciones de un Otro (indígena, negro, mulato, etc.), se pueden encontrar desde el siglo XVII a raíz de la conquista de las Américas. Según Grosfoguel este escenario puede ser descrito como "protoracismo", el cual emerge desde el siglo XVII como herencia de lo que él ha denominado el "racismo religioso", que se formuló como práctica para la conquista de Al-Ándalus. Grosfoguel advierte que, a partir de la discusión entre Ginés de Sepúlveda y Bartolomé de las Casas en la Escuela de Salamanca, en 1552, a razón de la pregunta sobre la humanidad del indígena, dada la condición otorgada por la conquista de ser un sujeto sin alma-no humano, se presenta en las Américas una primera discusión que tiene una condición de racismo biológico. El debate tiene como decisión final que los indios tienen alma, pero son bárbaros por cristianizar. Para Wieviorka (2009) este protoracismo tiene como característica fundamental la inferiorización, a raíz del "entorno en que viven: clima, naturaleza, pero también la cultura y la civilización en la cual han sido socializados" ( $p$. 23).

6. Se puede ver cómo en el siglo XIX se mantiene la lógica de una soberanía establecida por el imperio español, el cual no solo utilizó el poder soberano (dominio, imperio y gobierno sobre un territorio), sino que se acompañó del poder pastoral, el cual tenía la función de ejercer el dominio sobre las almas. Se debe entender que, si bien estos dos poderes guardan diferencias, entraron juntos a las Américas en el afán de ejercer control sobre el territorio conquistado y sobre los cuerpos de los seres humanos. Siguiendo a Foucault (2006), se puede definir al poder pastoral como el "gobierno cotidiano de los hombres en su vida real con el pretexto de su salvación" (p. 177). 
sometimiento del sujeto y la legitimidad de la ley" (Foucault, 2008, p. 50), siendo esto llamado por el filósofo francés como la emergencia de las "relaciones de poder", las cuales estarían acompañadas por la interseccionalidad de las relaciones de dominación de raza, clase, sexualidad y género.

A raíz de esta interseccionalidad de las relaciones de dominación, emerge en el contexto de la geografía racializada colombiana la zona del no-ser. Para la élite criolla, esta zona justificó la existencia de un ser-inferior que tenía como característica central su salvajismo. Los sujetos que habitaban la zona del noser serían presentados como seres sanguinarios y feroces, asimilando su existencia a una vida en estado natural; bajo esta concepción, el indio, el negro y el mulato no pertenecían a una sociedad civil, dado que estos eran "instintivos y siempre proclives a los excesos, eran por naturaleza seres indisciplinados" (Múnera, 2020, p. 97).

A raíz de estos argumentos, el racismo emerge como dispositivo fundante del Estado y de la nación colombiana, entendiendo que este se establece, según Grosfoguel (2012), a partir de una "jerarquía global de superioridad e inferioridad sobre la línea de lo humano que ha sido políticamente producida y reproducida como estructura de dominación durante siglos por el sistema imperialista, capitalista, patriarcal, moderno-colonial" (Grosfoguel, 2012, p. 93) ${ }^{7}$.

La configuración de un orden social y territorial racializado como estructura del Estado-nación colombiano crea una línea imaginaria que divide la realidad social en dos universos, a esto Santos (2014) lo denominó "pensamiento abismal". Siguiendo al sociólogo jurídico portugués, la creación de esta línea divisoria produce como efecto la no-existencia de aquello que supuestamente amenaza la modernidad-occidental. Es por ello que la historia y la memoria de los pueblos originarios fueron puestas en el lado de la no-existencia, lo que significó para los mismos la exclusión radical del Estado-nación; es decir, la imposibilidad de la copresencia al lado de la línea que se consideraba civilizada, blanca y moderna.

De esta manera, el racismo biológico y cultural emerge en el Estado-nación colombiano como aquel dispositivo de dominación de superioridad/inferioridad sobre la línea de quién era considerado como humano/no humano, civilizado/salvaje, etc. Por lo tanto, la naciente nación se construyó mediante una jerarquía que no solo expresa la permanencia del colonialismo, entendido este como una "relación política y económica que involucra la soberanía de un pueblo o una nación" (Walsh, 2012, p. 98), sino que produce lo que Quijano (2000) Ilamó "colonialidad del poder", que puede ser entendida como un patrón de poder ligado al capitalismo mundial, al control, la dominación y la subordinación de la población mediante el dispositivo de raza.

\section{Regeneración, modernidad y colonialidad: Cepillando la historia a contrapelo}

En el contexto de consolidación del Estado-nación colombiano, los misak ${ }^{8}$, como los demás pueblos originarios, no solo se enfrentarían a las guerras intestinas que marcaron

7. Se puede ver a lo largo del mundo todo un desarrollo conceptual, teórico y epistemológico que intenta mostrar la necesidad de conservar la hegemonía de la raza blanca; así, en Francia, Ernest Renan (2010) y otros se esfuerzan en justificar la consolidación de la nación a partir de la oposición racial. De igual modo, entre los años 1853-1855, Arthur de Gobineau, en su famoso Ensayo sobre las desigualdades de las razas humanas (2014), desarrolla un ejercicio epistemológico sobre la decadencia de la humanidad, a partir de lo que él denominó la "mezcla de las razas", factor que para el autor conllevaría al exterminio. 
el fin del siglo XIX y comienzos del XX, sino al lenguaje, a las prácticas y estrategias que se introducen en lo político-nacional en el afán de consolidar el ejercicio constitucional que consagraría en 1886 la supuesta unión del pueblo colombiano. Bajo este presupuesto constitucional emerge en el entramado del nuevo Estado-nación de corte centralista "la regeneración", concepto que marcaría la historia y la memoria estatal, así como la indígena, sobre todo la de los pueblos originarios en el departamento del Cauca?.

La "regeneración" sería utilizada como acto fundante ante la necesidad de consolidar a la nación dentro de un orden social, político, económico y territorial. En este orden de ideas, fue presentada como tabla de salvación ante la inminente catástrofe heredada por los intentos de consolidar un Estado que giró alrededor de los intereses de los grupos de poder que se establecieron durante el siglo XIX, quienes se enfrentaron en el afán de consolidar la organización político-administrativa que se argumentaba desde el centralismo y el federalismo.

Ante el desorden que produce la guerra, la idea de la "regeneración" es consagrada por Rafael Núñez mediante la promulgación de una Constitución Política que durante un siglo trazó un proyecto histórico a través de distintas prácticas de dominación, perpetuando una visión particular del poder y del Estado.
De este modo, el discurso político que emana de la Constitución Política de 1886 será interpretado como una manera de "educar, pacificar y disciplinar" (Melgarejo, 2008, p. 280), que en materia indígena resultaría en la vieja estrategia colonial que consistía en "civilizar al otro".

El discurso que emerge de la "regeneración" instaura en el nuevo imaginario de la nación colombiana una idea hegemónica de sociedad en la cual existen algunos sujetos que son considerados como desordenados, analfabetas, violentos, incivilizados e indisciplinados, que deben ser transformados ante la inminente necesidad que se tiene de entrar a la peculiar noción moderna del progreso, la que se materializa en un espacio temporal que se presenta como un ámbito homogéneo y vacío dentro del que solo tienen lugar un tipo de acontecimientos: los producidos por la modernidad.

En este caso, los acontecimientos provocados desde el mundo indígena serán considerados como un obstáculo para la vida de la nueva nación; es decir, estos serán objetados en el sentido de que atentan contra la moral del orden establecido para el ciudadano, mostrando que el locus de enunciación indígena se mantenía a la sombra de lo que será considerado como una sociedad en decadencia. Como bien lo expresa Melgarejo (2008), la "regeneración" permite ver los dos gestos

8. Esta comunidad se encuentra ubicada en el territorio del resguardo de Guambía, en jurisdicción del municipio de Silvia, en la región centrooriental del departamento del Cauca, sobre el flanco occidental de la cordillera Central, a una altitud promedio de $2527 \mathrm{~m}$. El resguardo tiene una extensión de $662,4 \mathrm{~km} 2$. Es habitado, según el plan de salvaguarda misak de 2014, por 23 mil personas y conforme al censo de 2018, por 21711 personas que se autodenominan pueblo misak.

9. Es importante señalar que el Cauca, y de manera especial su capital Popayán, se consolidó desde la época colonial como una sociedad aristócrata dado que esta ciudad, que para ese entonces se denominó como la provincia de Popayán, fue uno de los centros del poder en la Nueva Granada. Según Herrera (2009), la importancia de esta provincia se debió a su demarcación jurisdiccional, pues desde ella se establecieron relaciones con la Audiencia de Santafé y la de Quito. Lo anterior les permitió a los pobladores (hombres-blancos y propietarios) la creación de un sinnúmero de encomiendas y de minas de oro, generando todo un sistema de comercio del capital, así como la esclavización del indígena y del negro. A raíz de lo anterior, la Corona Española, en el afán de proteger la mano de obra indígena y de esta manera obligarlos a pagar tributo a cambio de una supuesta igualdad, crearía la figura del resguardo. Si bien los indígenas caucanos pagaron el tributo, estos siguieron siendo considerados como una raza inferior que debía ser separada de la raza superior blanca, creando lo que se conoció como pueblo de indios y de blancos, llamando a Popayán la "ciudad blanca de Colombia". 
del poder: "su gesto expansivo y así inclusivo, por un lado, y, por otro lado, un gesto exclusivo en relación con una población que, si no participa de la regeneración, quedará estancada y en estado de degeneración" (p. 281).

Para este momento de la historia del país los grupos indígenas soportarán todo el peso del progreso, peso que se caracteriza por la "presión sobre la tierra, puesto que la colonización se convirtió desde entonces en el mecanismo empleado por los terratenientes y legitimado por el Estado colombiano" (Vega, 2002, p. 25). De esta manera, el progreso aparece en el mundo indígena como acumulación primitiva, la cual no solo incurre en el despojo violento de la tierra, sino en la consolidación de una fuerza de trabajo que tiene como característica central "formas brutales y violentas de sometimiento, entre las que se desarrollan la servidumbre y la esclavitud" (Vega, 2002, p. 26).

A partir de este entramado geosociohistórico, los pueblos originarios de Colombia, entre ellos el misak, entrarían al siglo XX bajo el manto de la matriz de poder colonial que en el contexto de la "regeneración" estaría acompañada por el "positivismo y el darwinismo social" (Melgarejo, 2008, p. 282). Esta clasificación identitaria al servicio de los intereses de clase se caracteriza por la dominación social y por la capitalización de las relaciones sociales, configurándose en la base misma de los problemas que afronta el Estado-nación colombiano hasta nuestros días.

De esta manera, y siguiendo a Quijano (2000), lo que se establece en la "regeneración" es un sistema de "clasificación social basado en la categoría de raza como criterio fundamental para la distribución, dominación y explotación" (p. 34), que le sirvió al Estado-nación colombiano para la conformación de su estructura capitalista-global del trabajo. A partir de este momento la colonialidad del poder se configura en Colombia y de manera particular en el departamento del Cauca como una "división identitaria racializada, con el blanco (europeo o europeizado masculino) en la cima, seguido por los mestizos y, finalmente, por los indios y negros como último peldaño" (Walsh, 2012, p. 99).

El departamento del Cauca, al entablar su proceso moderno-colonial-capitalista "reproduce una especie de estructura invariante donde el indígena es puesto en estado de inferioridad a partir del dispositivo de raza" (Dávila, 2021, p. 68), lo que fue determinante para el borramiento del tiempo-espacio de la memoria y de la historia misak, al ser considerados como producto de un pasado anacrónico y salvaje que ataba a la nación en su afán de alcanzar el progreso.

Esta noción de progreso lineal homogéneo propio de la modernidad latinoamericana, refuerza en el Cauca la visión de superioridad del hombre blanco sobre la naturaleza y sobre el indígena, lo que permitió la emergencia de la colonialidad del saber y del ser, posicionando al "eurocentrismo como perspectiva única de conocimiento, que descarta y descalifica la existencia y viabilidad de otras racionalidades epistémicas y otros conocimientos" (Walsh, 2012, pp. 99-100) y, de igual manera, se legitima la inferiorización, subalternización y deshumanización, generando con ello lo que Fanon (2011) denominó el "trato de la no-existencia". De este modo, la coIonialidad del ser "apuntala a la relación entre razón-racionalidad y humanidad: los más humanos son los que forman parte de la racionalidad formal moderna característica del individuo «civilizado»" (Walsh, 2012, p. 100).

De este modo, la colonialidad del poder, del saber y del ser, configura en el Cauca del siglo XX un orden social, político, económico y territorial patrimonialista, el cual es 
considerado por la élite caucana como la base en la formación tributaria que los articula al sistema mundo a través de la acumulación por despojo, siendo entendida esta como el "motor que mueve el crecimiento bajo el modo de producción capitalista" (Harvey, 2014, p. 256). Parafraseando a Dávila (2021), el territorio caucano se ordena a través de relaciones de poder que combinan la servidumbre y el esclavismo de la población indígena con la expropiación de la tierra y el extractivismo epistémico y de materias primas.

A raíz de este régimen del capital local caucano, aparecen prácticas como el terraje, el cual ha sido explicado por la antropología como "una relación de carácter feudal servil, en donde el indígena debía pagar en trabajo gratuito dentro de la hacienda, el derecho a vivir y usufructuar una pequeña parcela, ubicada en las mismas tierras que les fueron arrebatadas" (Vasco, 2008, p. 372) ${ }^{10}$.

En medio de las relaciones de poder económico, político y territorial que se establecieron en el Cauca a través de la hacienda, emerge a mediados del siglo XX la presencia indígena en cabeza de Manuel Quintín Lame. Quintín Lame, hijo de terrazgueros, había vivido desde su infancia las consecuencias del terraje, separándolo de la vida comunitaria indígena. Como bien lo menciona Bonilla (1982), desde este lugar de ausencia de su mundo indígena, Quintín Lame se percata de la necesidad de regresar a sus orígenes. Esto llevó a que este líder histórico del movimiento indígena del Cauca idealizara la "vida, las costumbres y la raza indígena" (p. 26).
Al reconocerse como indígena colonizado por la esclavitud del terraje, el legalismo y la religión occidental, instituciones que han servido en la estructuración del racismo en el Cauca, Quintín Lame constituyó un sistema de ideas que se puede "calificar de puro indigenismo" (Bonilla, 1982, p. 26), lo que significó en su lucha "cepillar la historia a contrapelo"; es decir, "mirar con mucho cuidado y profundidad hacia atrás, para ver las heridas, las cicatrices escondidas debajo de la superficie lisa de la historia" (Gandler, 2014, p. 55). De esta manera, el pasado indígena se constituiría para él en una nostalgia por las formas de vida indígena.

Con la aparición de este líder, la historia del Cauca comenzó a re-escribirse. La memoria colectiva indígena emerge como lugar que tensiona la historia oficial estatal, que empieza a ser percibida por los pueblos originarios como "deslegitimación del pasado vivido" (Nora, 2008, p. 21). Quintín Lame, entre mingas, velorios, memoriales, protestas y peticiones, mostró a la memoria indígena como vida, encarnada en el mundo vivo de su pueblo, considerándola como un ejercicio dialéctico entre el pasado y el presente.

Se puede decir que Quintín Lame conquistó la memoria para la liberación del indígena, una liberación que tenía como fin la defensa de los resguardos y la recuperación de las tierras ocupadas por los terratenientes. Esto lo llevó a que fuera considerado por misioneros y hacendados como un "subversivo racial" (Romero, 2006, p. 21). Este apelativo, más que ser un mecanismo de deslegitimación, conduce a mirar el movimiento de Quintín

10. Se debe tener en cuenta que estas tierras estaban ubicadas en los resguardos, instituciones de carácter colonial, que fueron instauradas por la Corona Española en el siglo XVII con el fin de salvaguardar la vida de los pueblos originarios, que estaban muriendo en las mitas y encomiendas. Con este anclaje colonial los indígenas empezarían a tributar y a adquirir ciertos derechos que les permitió enfrentar los tratos crueles del encomendero. El resguardo en la actualidad tiene como una de sus principales funciones territoriales y administrativas la protección de la propiedad colectiva sobre la tierra. El resguardo de Guambía, ubicado en el municipio de Silvia (Cauca), fue constituido mediante Cédula Real. Estas tierras, hasta el día de hoy, se consideran como propiedad colectiva y no enajenable, según el artículo 329 de la Constitución Política de 1991. 
Lame como un pensamiento que se sale de la lógica del tiempo lineal homogéneo orientado hacia el futuro; es decir, conduce a la lucha indígena del Cauca a interrumpir el paso del progreso.

De esta manera, se puede insinuar que la lucha indígena en el Cauca contradice de cierta manera a Marx, pues este dice que las revoluciones son las locomotoras de la historia mundial, pero Quintín Lame se encuentra con Benjamin para objetar la postura de este pensador y a contrapelo responden que "tal vez las revoluciones son el momento en el cual el género humano, que viaja en ese tren, acciona el freno de emergencia" (Benjamin, 2009, p. 71).

La llama del pensamiento telúrico, como fue llamada también la revolución indígena de Quintín Lame, despierta la conciencia de las comunidades indígenas que habitan el Cauca. Si bien Quintín Lame se reconocía como parte de la cultura indígena Nasa, influyó en el pensamiento de varios jóvenes indígenas misak como el tata Javier Calambás, el tata Lorenzo Muelas, el tata Avelino Dagua, y la mama Faustina Muelas, quienes se congregaron alrededor de este pensamiento que tenía como centro la existencia de "una ligazón vital entre la tierra y el indio; mejor aún, entre la tierra y la comunidad" (Romero, 2006, p. 23). De allí que la lucha indígena que germina en el Cauca tenga como concepto central "recuperar la tierra para recuperarlo todo".

Este recuperar la tierra para recuperarlo todo no solo implicó para los misaks la recuperación de su resguardo y la consecución de nuevas tierras para seguir ejerciendo su vocación de agricultores, vivir y trabajar en paz, sino todo un contexto vital y cultural que venían perdiendo a raíz del modelo excluyente de la matriz de poder moderna-colonial. Por eso los misaks, como el ángel de la historia de Benjamin, miran hacia atrás: porque solo del recuerdo de las represiones y humillaciones del pasado se puede sacar una fuerza política que no se deje someter tan fácilmente.

Es por ello que el tata Jeremías Tulumbalá, exgobernador del pueblo misak, muestra la permanencia y la existencia de su pueblo a través de su proceso de resistencia que se traduce en una frase que refleja su convicción de vida: "nuestra lucha es nuestra vida"; seguidamente él explica: "porque desde que uno nace, vive dentro de otro Estado, estás obligado para toda la vida a luchar, estamos condenados a vivir siempre luchando, así nos hayan reconocido derechos, así exista representatividad política, pero siempre lucharemos por nuestra forma de vida" (Comunicación personal, 2017).

\section{Los misaks: entre el pasado y el presente}

El territorio caucano, para los años cincuenta, se convirtió en escenario de conflictos y tensiones. Como lo expresa Dávila (2020), los misaks, como los demás pueblos originarios, no solo se encontraban con su propia lucha en el "afán de terminar con el régimen del terraje" (p. 171), sino que sufrían la violencia partidista que se había generalizado en todo el país, así como los discursos geopolíticos que tras el nuevo paradigma desarrollo/progreso, impartían una serie de políticas que señalaban los lineamientos para que los países de América Latina salieran del subdesarrollo.

Parafraseando a Escobar (2012), estas políticas que se impulsaban a partir del discurso desarrollo/subdesarrollo para el avance de las sociedades latinoamericanas que se traducían en "altos niveles de industrialización y urbanización, tecnificación de la agricultu$r a$, adopción generalizada de la educación y de los valores modernos" (p. 27), seguían 
considerando a los pueblos originarios como obstáculos, de allí que el discurso promovido por las Naciones Unidas en 1951, encaminado a la promoción del desarrollo económico de América Latina, mostraba la necesidad de hacer "ajustes dolorosos", lo que implicaba que las "filosofías ancestrales deben ser erradicadas y las viejas instituciones sociales tienen que desintegrase" (Naciones Unidas, 1951, p. 15, como se citó en Escobar, 2012, p. 28).

Bajo este panorama global, nacional y local, el Cauca entró bajo una pluralidad de dinámicas que marcaron la segunda mitad del siglo XX. Según Dávila (2020), algunos sectores del naciente movimiento indígena se encontraron con una serie de conceptos ideológicos que fueron encaminados para la "recuperación de la tierra", entre ellos el cooperativismo agrario, el cual fue iniciado bajo el liderazgo del tata Javier Calambás, mediante el cual los misaks compraron la primera tierra hoy denominada como "Santiago", mediante la Federación Agraria Nacional (FANAL) ${ }^{11}$.

También cabe anotar que el discurso revolucionario de la época, que proclamaba "la combinación de las fuerzas de luchas", tocó al movimiento indígena, lo que significó en su momento una defensa armada de los territorios, que fue acompañada por el clamor de una reforma agraria. En el ámbito de la revolución agraria de las décadas de los sesenta y los setenta, los misaks, haciendo caso de su esencia histórica de ser un pueblo pacífico, introducen en el ambiente de la lucha indígena lo que ellos denominan "insumisión" que, de acuerdo con Dávila (2020), significa "reunir fuerzas, organizar y organizar más para llegar a algo concreto" (p. 171).
Lo anterior representó para la comunidad misak "enconcharse"; este fenómeno social, político y cultural significó en estas décadas encontrarse con una memoria viva que cambia la idea de sentido de la historia construida desde los vencedores, en donde "el pasado está cerrado, se ha concluido en el presente y por ello las posibilidades históricas se encontrarán en futuro, como distantes y remotas esperanzas" (Reyes, 2014, p. 118).

A raíz de lo anterior, se puede interpretar que los misaks asumieron su historia y su memoria asociadas a la noción de experiencia; es decir, la insumisión se presenta como respuesta emancipatoria y de liberación de la matriz de poder colonial, lo que implicó para ellos como comunidad en resistencia ver su pasado como un "conjunto abierto de posibilidades para el presente" (Reyes, 2014, p. 118), en el sentido de que la historia y la memoria de su pueblo es vista como una narración constante y duradera que permite ser transmitida en el afán de recuperar la tierra, la territorialidad y su identidad.

Según Benjamin (2009), la historia propuesta desde la memoria viva y resistente misak se constituye en un "marco de tensiones entre lo alcanzado y lo malogrado, ambos como parte de la dialéctica de un proceso opaco y tentativo" (p. 71). En esta perspectiva, este pueblo originario recupera desde la memoria un tiempo que se contrapone al del historicismo como tiempo vacío y continuo. Parafraseando a Benjamin (2009), el pasado y el presente dejan de ser salas de espera para la llegada del futuro y los espacios dejan de ser un contenedor de los acontecimientos; al contrario, el espacio-tiempo de la memoria

11. En entrevista realizada en el 2017 al tata Javier Calambás, líder histórico de la resistencia misak, cuenta sobre la primera acción que tuvo lugar en Silvia (Cauca) con el fin de recuperar la tierra: la compra de la hacienda La Selva, que era propiedad de la familia Garrido, considerados por la comunidad como terratenientes. Este hecho se constituyó en el inicio no solo de la recuperación de la tierra, sino de los cabildos, resguardos y el territorio ancestral misak. 
misak es asumido como la posibilidad de transformación de la historia.

Teniendo en cuenta el sentido del espacio-tiempo misak y su emergencia como sujetos históricos, en el entramado de relaciones de poder que se configuran en el departamento del Cauca, este pueblo que se denomina como "los hijos del aroiris y del agua" no solo recupera la tierra como medio de producción y subsistencia, sino que establece un orden territorial autonómico, político, social y económico alrededor del "Nupirau" (territorio), el cual es considerado como "el primer lugar del mundo en el cual nació la vida misak" (Segundo Manifiesto Misak, 2014).

Para los misaks el territorio es parte importante para el desarrollo de la autonomía y la autodeterminación comunitaria, es por eso que el Nupirau es considerado como la casa grande, el cual está conformado por cuatro espacios básicos para la vida de la comunidad. De conversaciones con la mama Liliana Pichecué, la mama Faustina Muelas, el tata Javier Calambás y el tata Jeremías Tulumbalá, se puede insinuar que estos espacios emergen en el contexto de la lucha a través de la memoria del dolor que, como menciona Benjamin (2009), apuntala a la "salvación, a la redención de lo posible", dando una cita secreta entre las generaciones misak pasadas y las presentes.

Como bien lo dice Amengual (2018), la memoria del dolor se convierte en un "acto de reparación y en promesa de redención" (p. 44), precisamente porque los derechos arrebatados al pueblo originario misak no podían quedar pendientes, de allí que su lucha histórica parta de un pasado que le exige al presente un futuro de esperanza. De este modo, los cuatro espacios configuran un proceso de acción política que le devuelve la esperanza al pueblo misak través de los tres ejercicios de la memoria: "el recordar, rememorar y conmemorar" (Amengual, 2018, pp. 35-40).

Al adentrarse al Nupirau, a la casa grande misak, y de caminar atrás de los mayores y las mayoras empieza a develarse lo que se denominará en este artículo como una "pedagogía insumisa". Esta pedagogía que es territorializada a través de los espacios de la memoria misak emerge en el entramado del territorio de la siguiente manera:

Un primer espacio común, que es símbolo de la unidad comunitaria, de la familia, el segundo espacio Yak tull o conocido como sementera, este expresa la economía de la comunidad, el tercer espacio Pikap o ojo de agua, con una fuerte relación con la vida Misak, este espacio invita a compartir con quien necesita de la comunidad y el cuarto espacio el Nachak 0 fogón, este es el lugar de reunión de todos, de compartir, intercambiar, comentar, los acontecimientos de la familia y de la comunidad, es decir, socializar. (Segundo Manifiesto Misak, 2014)

De esta manera, los espacios misak han devenido en lugar, dado que implican un vínculo entre la memoria y la historia. Por lo tanto, estos espacios guardan la memoria, la transmiten a las generaciones futuras, en el afán de mantener vivo el recuerdo de la propia vida de su pueblo; de igual manera, al constituirse en lugares ancestrales-sagrados rememoran una historia creando una alianza entre pasado y presente, constituyéndose en la transmisión de una experiencia cuya comunicación crea comunidad. Finalmente, estos espacios de la memoria son los lugares de la conmemoración, de las fiestas, de los rituales; es decir, de la creación de su propio tiempo. 
Memoria misak:

\section{Una pedagogía insumisa}

(A manera de conclusión)

Detrás de la retórica de la diferencia cultural que deja el reconocimiento estatal mediante la promulgación de la Constitución Política de 1991, la lucha de los pueblos originarios y de manera particular el misak, se constituye en una memoria que es transformada en una acción ético-política organizada alrededor del territorio y de la tierra que tiene un triple deseo: identidad, autonomía y autodeterminación. Es por ello que los misaks no parten de una tabula rasa, sino de un pasado que les permite desde la diferencia crear posibilidades creadoras y recreadoras.

La presencia misak a través de su memoria viva se presenta ante el Estado-nación como un espacio-tiempo con categoría política y a la vez existencial; como lo menciona Achille Mbembe (2016), el tiempo de los pueblos subalternizados "es el punto de partida de un pensamiento del tiempo que se avecina" ( $p$. 158). Así, la memoria misak se proyecta hacia el interior de la comunidad y hacia el exterior de esta, como un pasado que funciona como motivo de inspiración de su resistencia; es decir, es utilizado como proyecto pedagógico en donde intervienen los saberes propios misak, que al ser territorializados configuran un conjunto de prácticas que operan como racionalidades singulares y heterogéneas de su identidad.

Desde lo que se puede denominar como una acción pedagógica, la memoria misak tensiona a la historia colonial y republicana impuesta por el colonialismo, la colonialidad, el patriarcalismo y el capitalismo, develando que estas se han caracterizado por su apetito de muerte. En contraposición a ello, la emergencia del pasado misak despliega dos tipos de "capacidades y prácticas: la esperanza y la imaginación" (Mbembe, 2016, p. 159).
Siguiendo al historiador sudafricano, la esperanza y la imaginación como deseo memorial comunitario misak le plantean al Estado-nación una distinción entre memoria de la esclavitud y la servidumbre (terraje, la acumulación por despojo), por una memoria de la liberación y la emancipación que puede ser entendida como la posibilidad de una nueva interioridad que se confronta a sí misma y a la exterioridad.

De este modo, el pasado que llega a través de la memoria misak, interpela la diferencia que ha sido vencida y humillada, porque en el fondo es una "diferencia que posee elementos que han sido ya objeto de una pérdida irreparable" (Mbembe, 2016, p. 159), desprendiéndose del carácter de víctimas históricas y evitando los esencialismos producidos por la evocación tanto de la misma comunidad como desde la sociedad moderna-colonial universalizante.

Visto de otra manera, la función de la evocación del pasado y de la diferencia no puede ser traducida en una memoria de museo, sino que debe considerarse una función liberadora. Parafraseando a M bembe (2016), el esencialismo también es una forma de alienación, y donde existe esta pervive la coacción; de este modo, la diferencia expresada y exigida desde el esencialismo es "portadora de sus propios gérmenes de muerte, de su finitud".

Es por eso que, desde la pedagogía insumisa, los misaks transforman su memoria del dolor a una memoria viva, vigilante, permitiéndose desde ella impedir la repetición. M bembe (2016) dice que estas memorias vigilantes "sirven para liberarse de la repetición de la alienación de la domesticación del ser humano, su reducción a la condición de objeto" (p. 160). En otras palabras, la memoria misak es éticamente militante, es una acción cotidiana, al ser la primera "categoría básica 
de la identidad [misak]" (Mèlich, 2001, p. 58). Pues sin la memoria solo hay muerte. Así la memoria se forma en un constante devenir, enrollando y desenrollando, como enseñan las mamas misak.

Por lo tanto, en la memoria misak la identidad se forma, pero no al modo de una identidad substancial sino como respuesta al otro, como respuesta al colonialismo y a la

\section{Referencias}

Amengual, G. (2018). Mantener la memoria. Herder.

Anderson, B. (2011). Comunidades imaginadas. Reflexiones sobre el origen y la difusión del nacionalismo. Fondo de Cultura Económico.

Arendt, H. (2019). Sobre la violencia. Alianza.

Benjamin, W. (2009). Estética y política. Editorial La Cuarentena.

Bonilla, V. (1982). Historia política de los paeces. Nuestra Ediciones.

Cuchumbé, J. (2012). El multiculturalismo de Charles Taylor y el universalismo de los derechos de Jürgen Habermas. Universidad del Valle.

Dávila, C. (2020). Tensiones jurisdiccionales: emergencias y transformaciones en las territorialidades de los pueblos indígenas y el Estado-nación colombiano. El caso Misak. Editorial Universidad de Caldas.

Dávila, C. (2021). Grupos étnicos: Luchas sociales, emergencias y disputas territoriales misak. Revista Vínculos. Sociología, análisis y opinión, 21(18), 59-87.

Escobar, A. (2012). Una minga para el postdesarrollo: lugar, medio ambiente y movimientos sociales en las transformaciones globales. Editorial Desde Abajo. colonialidad del poder a partir de una identidad narrativa que tensiona y conflictúa a la modernidad-colonial desde una diferencia, como espacio-tiempo, que no es solamente pasado, sino también presente y futuro. Por eso, la memoria misak no es nostalgia, porque interviene sobre la historia, rompiendo su linealidad, su historicismo, de allí que ella es recuerdo del pasado, crítica del presente y esperanza de un futuro liberador.

Foucault, M. (2008). Defender la sociedad. Fondo de Cultura Económica.

Gandler, S. (2014). ¿Por qué el ángel de la historia mira hacia atrás? Editorial Universidad Autónoma de México.

Giddens, A. (1987). Sociology: A Brief but Critical Introduction. Harcourt Brace Jovanovich.

de Gobineau, A. (2014). Ensayo sobre las desigualdades de las razas humanas. Sieghels.

Gramsci. A. (2013). Vidas rebeldes. Oceansur.

Grosfoguel, R. (2012). El concepto de racismo en Michel Foucault y Frantz Fanon: ¿teorizar desde la zona del ser o desde la zona del noser? Revista Tabula Rasa, (16), 79-102.

Grosfoguel, R. (2020). El extractivismo epistémico: un diálogo con Alberto Acosta, Leanne Betasamosake Simpson y Silvia Rivera Cusicanqui. Akal.

Grueso, D. (2009). Caldas y Caro: los roles del catolicismo y la ciencia en la negación de la diversidad de la nación colombiana. Editorial Universidad del Valle.

Guerrero, P. (2002). Guía etnográfica para la sistematización de datos sobre la diversidad y la diferencia de las culturas. Abya-Yala. 
Haesbaert, R. (2011). El mito de la desterritorialización. Del fin de los territorios a la multiterritorialidad. Siglo XXI.

Harvey, D. (2014). Espacios del capital. Akal.

Herrera, M. (2009). Popayán: La unidad de lo diverso. Territorio, población y poblamiento en la provincia de Popayán, siglo XVIII. Editorial Universidad de los Andes.

Jimeno, M. (2012). Etnografías contemporáneas. Trabajo de campo. Universidad Nacional de Colombia.

Lévinas, E. (2012). Totalidad e infinito. Sígueme.

Mançano, B. (2011). Territorios, teoría y política. En G. Calderón y E. León (coords.), Descubriendo la espacialidad social desde América Latina. Reflexiones desde la geografía sobre el campo, la ciudad y el medio ambiente (pp. 21-51). Editorial Ítaca.

Mbembe, A. (2020). Descolonizando el conocimiento y la cuestión del archivo. Una reflexión desde Sudáfrica. Akal.

Melgarejo, M. d. (2008). Trazando las huellas del lenguaje de la regeneración: la nación colombiana y el problema de su heterogeneidad excepcional. En S. Castro y E. Restrepo (eds.), Genealogías de la colombianidad. Formaciones discursivas y tecno (pp. 279306). Universidad Javeriana.

Mèlich, J. (2001). La ausencia del testimonio. Ética y pedagogía en los relatos del Holocausto. Anthropos.

Mèlich, J. (2015). La lógica de la crueldad. Herder.

Mignolo, W. (2007). La idea de América Latina. La herida colonial y la opción decolonial. Gedisa.

Múnera, A. (2020). Fronteras imaginadas. La construcción de las razas y de la geografía en el siglo XIX colombiano. Crítica.

Nora, P. (2008). Lex Lieux du mémoire. Trilce.
Olivera, A. (2014). Etnografía decolonial con colectivos charrúas: reflexionando sobre interconocimientos. Anuario de Antropología Social y Cultural, 12, 139-153.

Quijano, A. (2000). Coloniality of power, eurocentrism and Latin America. Neplanta: Views from south, 1(3), 533-580.

Quijano, A. (2014). Colonialidad del poder y clasificación social. Akal.

Rappaport, J. (2007). Más allá de la escritura: la epistemología de la etnografía en colaboración. Revista Colombiana de Antropología, 43, 197-229.

Renan, E. (2010). ¿Qué es una nación? Hidra.

Rivera, S. (2018). Un mundo ch 'ixi es posible. Ensayos desde un presente en crisis. Tinta Limón.

Romero, F. (2006). Manuel Quintín Lame Chantre. El indígena ilustrado, el pensador indigenista. Editorial Universidad de Antioquia.

Santos, B. (2003). La caída del Ángelus Novus: ensayos para una nueva teoría social y una nueva práctica política. Editorial Universidad Nacional de Colombia.

Santos, B. (2014). Más allá del pensamiento abismal: de las líneas globales a una ecología de saberes. Akal.

Santos, B. (2020). Las epistemologías del sur: dar voz a la diversidad del sur. Akal.

Segundo Manifiesto Misak (2014). Plan Salvaguarda. Autoridad, autonomía. Nu nachak. Comunidad misak.

Vasco, L. (2008). Quintín Lame: resistencia y liberación. Editorial Universidad Nacional.

Vega, R. (2002). Gente muy rebelde. Indígenas, campesinos y protestas agrarias. Ediciones Pensamiento Crítico. 
Walsh, C. (2020). Pedagogías decoloniales caminando y preguntando. Notas a Paulo Freire desde Abya Yala. Akal.

Wieviorka, M. (2009). El racismo: una introducción. Gedisa.

Yrigoyen, R. (2011). El horizonte del constitucionalismo pluralista: del multiculturalismo a la descolonización. Siglo XXI. 